\title{
Tensegrity Structure: Experimental Methodology for Wheelchair Design
}

\author{
Carlos Mauricio da Costa Ramos ${ }^{1, *}$, Raquel Barbosa Teixeira ${ }^{2}$, José Luiz Mendes Ripper ${ }^{3}$ \\ ${ }^{1}$ Department of Industrial Design, Federal University of Rio de Janeiro, Brazil \\ ${ }^{2}$ Department of Technical Drawing, Foundation to Support the Technical School, Brazil \\ ${ }^{3}$ Department of Arts and Design, Pontifical Catholic University of Rio de Janeiro, Brazil
}

Copyright $@ 2018$ by authors, all rights reserved. Authors agree that this article remains permanently open access under the terms of the Creative Commons Attribution License 4.0 International License

\begin{abstract}
This experimental research is inserted in the universe of people with special needs and intends to develop a new technology to design the structure of wheelchair. This structure consists of a tensegrity module composed of bamboo sticks and tensioned cables and adopts all the anthropometric standards with the observance to the ergonomic studies and individual needs of the use of the wheelchair users. This new concept of structure design, as it is unprecedented, results in an innovative product and allows new interpretations and unfolding. This research also initiates a new interpretation of tensegrity by its application to orthotics for rehabilitation that is currently widely diffused in the plastic arts, architecture, but incipient in product design. The use of tensegrity can meet some needs as a favorable body adaptation due to the malleability of the structure that absorbs the more sudden movements that can cause discomfort, injury and bad accommodation of the user to the wheelchair, besides providing a product of low cost and of easy production , because the structure is assembled by fit and wired.
\end{abstract}

Keywords Wheelchairs Projects, Tensegrity, Bamboo

\section{Introduction}

This research was the result of the doctorate of the author and had the objective to develop in the field of Design, new technologies (methods and techniques) that manage its application in objects of utility from the tensegrity structure that is widely used in the field of the plastic arts and architecture, but incipient in product development projects. Therefore, it is attempted to develop a wheelchair design that makes use of the tensegrity structure, taking advantage of the spring effect that it has and which has been proven by Fuller's research. The set of these tensegrity characteristics will allow a production without the need for rigid structures with metal welding and that, even in the scope of usability, add comfort and safety to the user of the wheelchair. The design methodology was based on ergonomic analysis for the development of the design of the test model and the production of the physical model for tests applied to wheelchair users. The author of this research began his research still in the graduation of Industrial Design when he designed the Stand-up Wheelchair [1], which has a mechanism that allows the user to stand independently. With this invention, the author opened a factory to produce the Stand-up Wheelchair, where he acquired specific expertise and knowledge in the wheelchair manufacturing process. This knowledge began as a starting point for his master's thesis entitled "Wheelchairs: a Design and Prescriptive Approach", where he can deepen the ergonomic and usability aspects in wheelchairs and subsequently make his doctorate possible. Thus, the experience acquired in 35 years of research, projects and production of products in the area of rehabilitation gave the author of this research sufficient knowledge of the whole process of wheelchair manufacturing that were fundamental to reach the conclusion that the chair wheels with tensegrity structure has a simpler production process and more affordable cost compared to the manufacturing process of a conventional wheelchair. In this way, the wheelchair of tensegrity structure can be an alternative for users of emerging countries and also of lower classes of any country. However, by its visual and ecological appeal the tensegrity wheelchair can seduce people of all social and economic classes. 


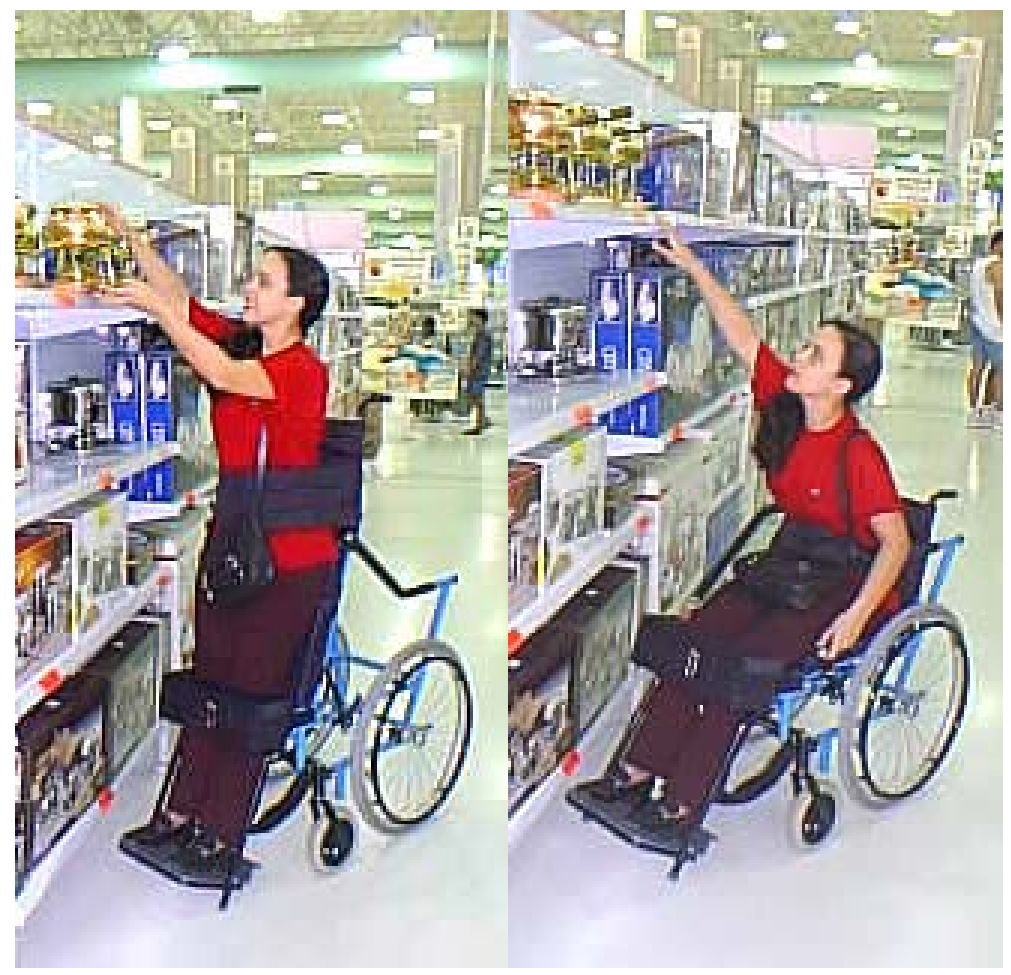

Figure 1. Stand-up Wheelchair - prepared by author

\section{Aspect of Tensegrity and Bamboo}

\subsection{Aspect of Tensegrity}

Tensegrity is the name given to describe physical structures assembled by rigid sticks that do not touch each other and are kept in their place by traction cables. This name was given by Fuller [2], an architect and scholar of this type of structure. In these structures, the parties not to support each other and are connected by flexible cables, produce the effect of spring, being that its main feature and observed in this research. There are some basic arrays of shapes of the system that it calls basic cell. Which were developed by Snelson [3], as shown in Figure 2.
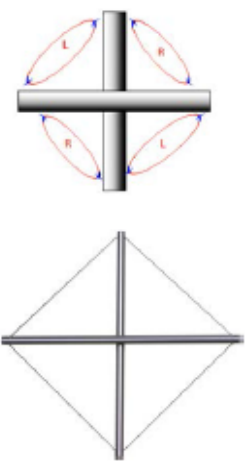

X-MODULE; COMPLETE TRIANGULATION
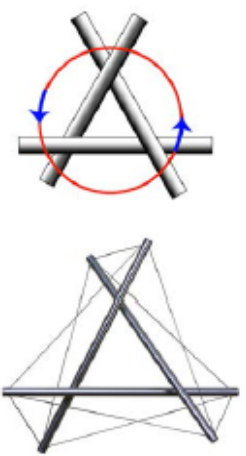

3-WAY PRISM; COMPLETE TRIANGULATION
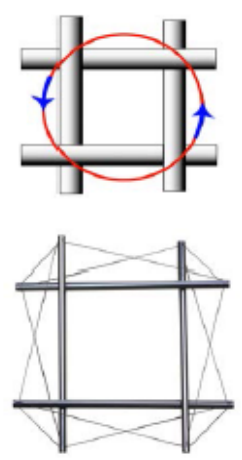

SQUARE PRISM; SQUARES ARE NON-TRIANGULATED
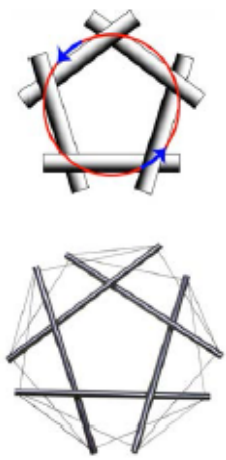

PENTAGONAL PRISM; PENTAGONS ARE NON-TRIANGULATED
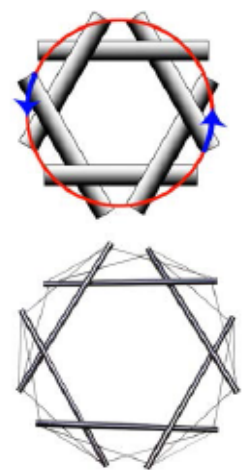

HEXAGONAL PRISM; HEXAGONS ARE NON-TRIANGULATED

Figure 2. Cell combinations tensegrity - Snelson, biography 
This characteristic of being flexible was fundamental to the initiative of using a tensegrity structure in a wheelchair. The mechanical capacity of a tensegrity structure is notorious as well as, the cost benefit and weight, but it can be critical to the wellbeing of the wheelchair user. And it is on this aspect that was based one of the hypotheses and objectives of the research. The flexibility cannot be confused with loss of structural form, quite the contrary, the characteristic of tensegrity is always to return to its initial form after suffering some deformation. It is a perfectly elastic system, according to figure 3.

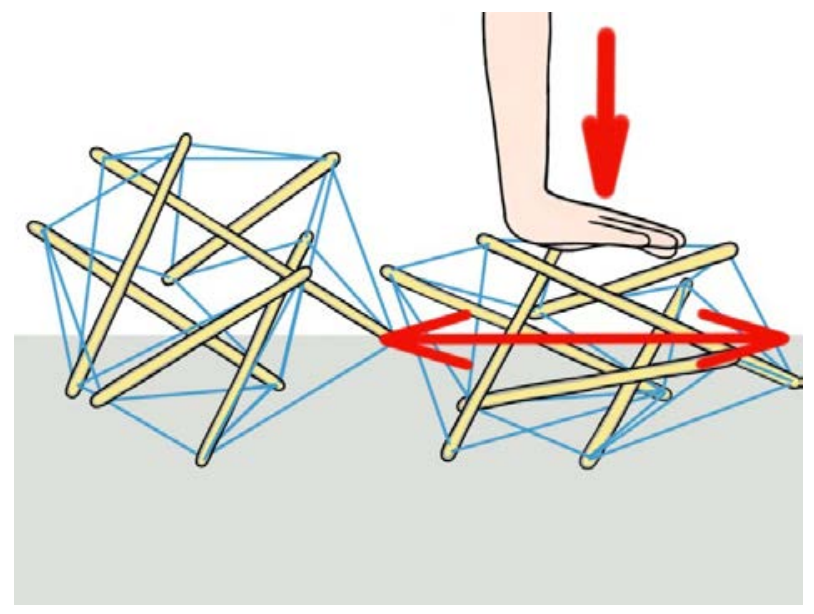

Figure 3. Demonstration of the malleability and resilience of the tensegrity structure - prepared by author

The engineer, architect and designer Richard Buckminster Fuller was the first scholar of these structures, now known as tensegrity, in the 1920s. One of his greatest contributions was the development of a spherical tensegrity (Figure 4) model that served as a starting point for other studies of his time onwards, becoming the main reference in this area.

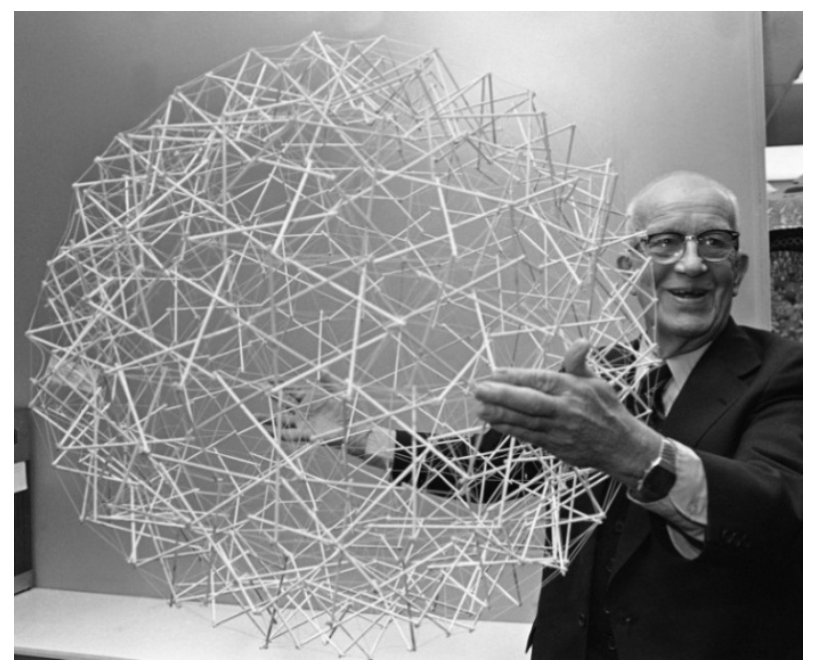

Figure 4. Tensegrity spherical, 1927 - Fuller

The model used in this research the steel cables are drawn and consequently compress the bamboo keeping the structure integrates perfectly adjusted as shown in figure 5 . In item 3 it will be demonstrated because the tensegrity model chosen was the best option among several existing ones.

As the bamboos do not touch when the structure receives some pressure the whole structure (bamboo, steel etc.) is free to move and distribute the forces acting on the structure in order to cancel out its effects. Another important factor for the maintenance of the integrity of the structure is its resilience capacity, because when the forces cease the structure returns to its initial shape.

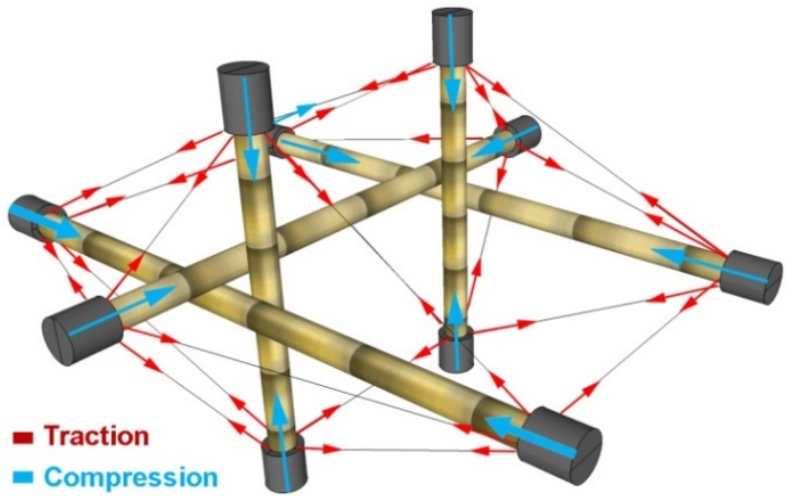

Figure 5. Distribution of forces in the tensegrity structure - by author

According to Fuller (1995) these systems work in the light of a synergy where their behavior is not dictated by any of its components separately, but by the sum and cooperation, in the divergence and convergence of the parts for the same purpose. In Synergy the value of the set of components of the whole is greater than the value of each part individually.

\subsection{Aspect of Bamboo}

To realize the benefits of the application of bamboo in relation to steel, for example, bamboo offers a tensile strength versus specific weight 2.77 times more than steel, as reported in the table below withdrawal of Gavami's research [4].

Table 1. Tensile strength Ratio X specific gravity; Source: 1992 Ghavam

\begin{tabular}{|c|c|c|c|c|}
\hline Material & $\begin{array}{c}\text { Tensile } \\
\text { strength } \\
(\mathrm{Mpa})\end{array}$ & $\begin{array}{c}\text { Specific } \\
\text { weight } \\
\left(\mathrm{gf} / \mathrm{cm}^{3}\right)\end{array}$ & $\mathbf{R}=\left(\boldsymbol{\sigma}_{\mathrm{t}} / \boldsymbol{\gamma}\right) \mathbf{1 0}^{-2}$ & $\begin{array}{c}\mathrm{R} / \mathrm{R} \\
\text { steel }\end{array}$ \\
\hline Steel & 500 & 7,83 & 0,63 & 1,00 \\
\hline Bamboo & 140 & 0.80 & 1,75 & 2,77 \\
\hline Aluminum & 304 & 2,70 & 1,13 & 1,79 \\
\hline Cast Iron & 281 & 7,20 & 0,39 & 0,62 \\
\hline
\end{tabular}

Another advantage is the relationship between the specific weight Vs. resistance. A comparison based on production per unit of power voltage for building materials shows a bigger difference reaching 50 times, as shown in the table below withdrawal of Gavami's research [4]. 
Table 2. Power Relationship of production per unit of voltage; Source: 1992 Ghavami

\begin{tabular}{|c|c|c|c|c|}
\hline Material & Bamboo & Woody & Concrete & Steel \\
\hline $\mathrm{M} / \mathrm{m}^{3} / \mathrm{MPa}$ & 30 & 80 & 240 & 1500 \\
\hline
\end{tabular}

Bamboo is a tropical plant that has a renewable annual cycle of reproduction without the need for replanting, in addition to being the natural resource that is renewed in less amount of time, in the absence of any other species of forest plant that can equate in growth rate and of for planting area. For these features bamboo is a great agricultural potential and that consequently presents itself also with great potential for application in large scale by industry. In addition to being an efficient carbon fixation, has excellent physical, chemical and mechanical characteristics.

\section{Methods of Project Development}

For the development of the tensegrity structure, a tensegrity model developed by the doctoral advisor (Figure 6) prof. Ripper in the 1970s. The chosen model has already been the subject of successful research in other opportunities for making tents, but never for the design of a wheelchair. The definition of the model was given by the physical characteristics, which are shown in item 3, since they combine with the structure and needs of a wheelchair. The necessary parts (wheels etc.) fit perfectly, as can be seen in the descriptions in the following set of images.

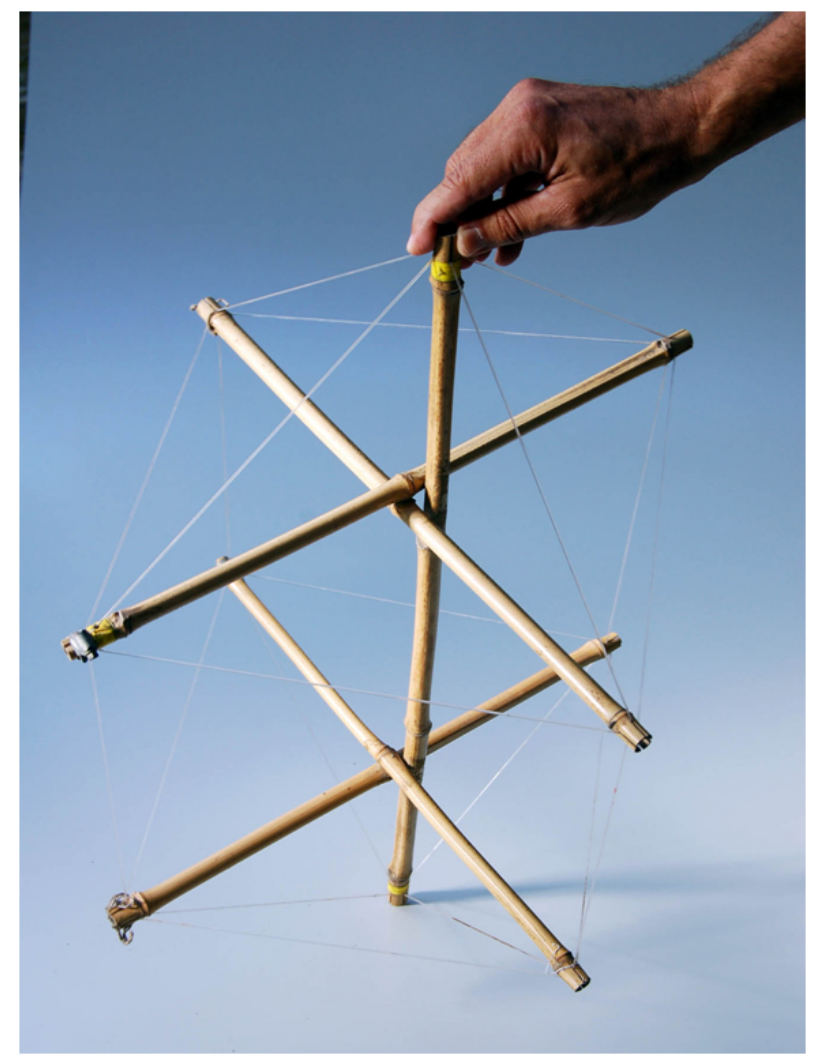

Figure 6. Tensegrity original of Prof. Ripper - prepared by author
Set the tensegrity module the project focused on defining a position coincide the anchoring points of the set of use (set the backrest, seat and footrest in metal) with the sticks of tensegrity module, and tensegrity allows a multitude of positions that can be seen in three dimensions which makes the definition of the ideal position. So, the first step was to analyze the two structures, tensegrity and set to use, and check the possible coincidences. Forming itself and especially the front wheels provided the path to follow. The front wheels are positioned parallel to the front of the wheelchair and the tensegrity module has two pairs of parallel rods. From that coincidence both configuration structures, were attempted a series of positions to find the ideal position. One of them was to position the tensegrity module horizontally so that pairs of parallel rods stay parallel to the ground, as shown in figures 7 and 8 .

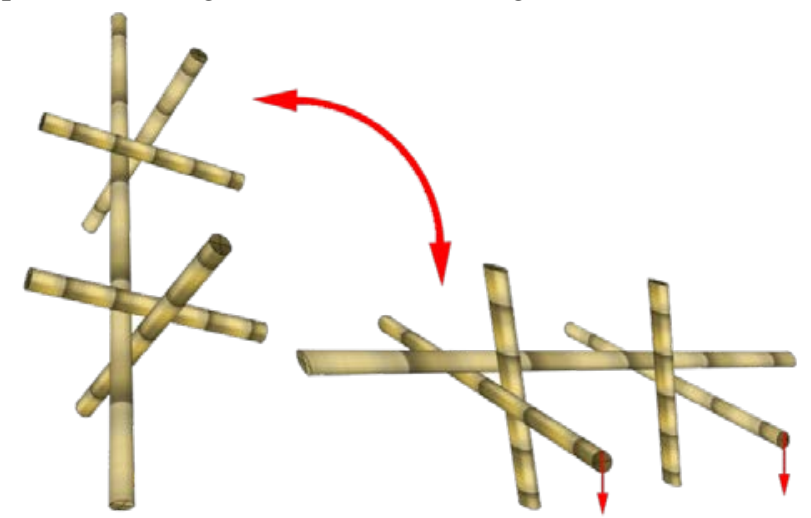

Figure 7. Tensegrity rotated parallel shafts down coincident with the front wheels - prepared by author

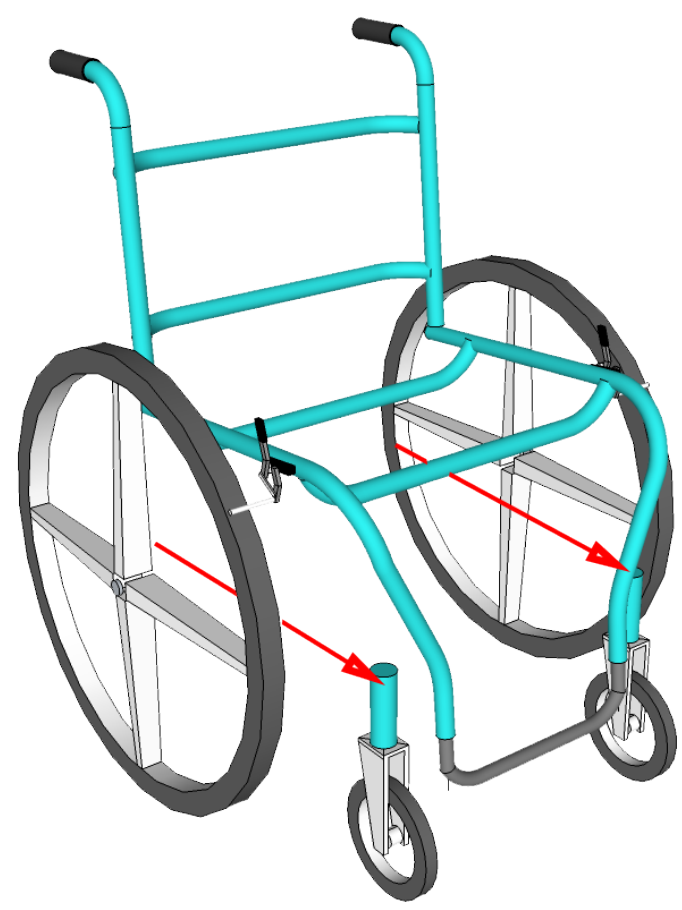

Figure 8. Coincidence of the front wheels position with parallel rods prepared by the author

The drop seen in the previous figure, not only defined 
the coincidence of the sticks with the front wheels, but stressed also the positioning of tensegrity fitting with the set of use at the top by the position of the other two parallel matching bamboo stalks, as shown in figures 9 and 10 .

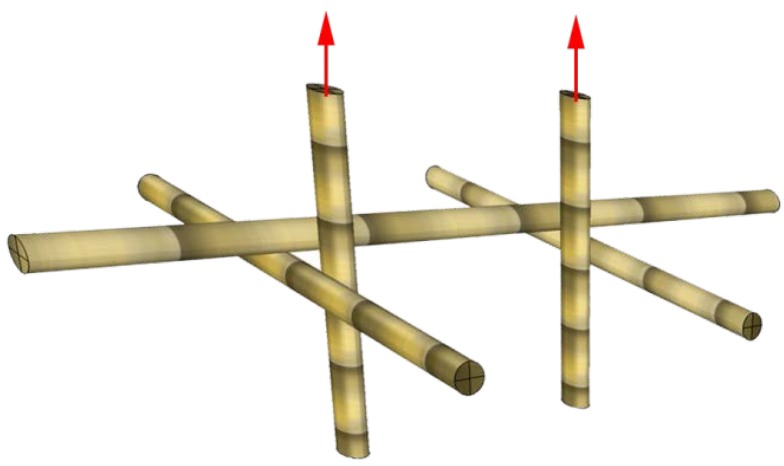

Figure 9. Tensegrity Module with coincidence of vertical bamboo poles with the use - prepared by the author

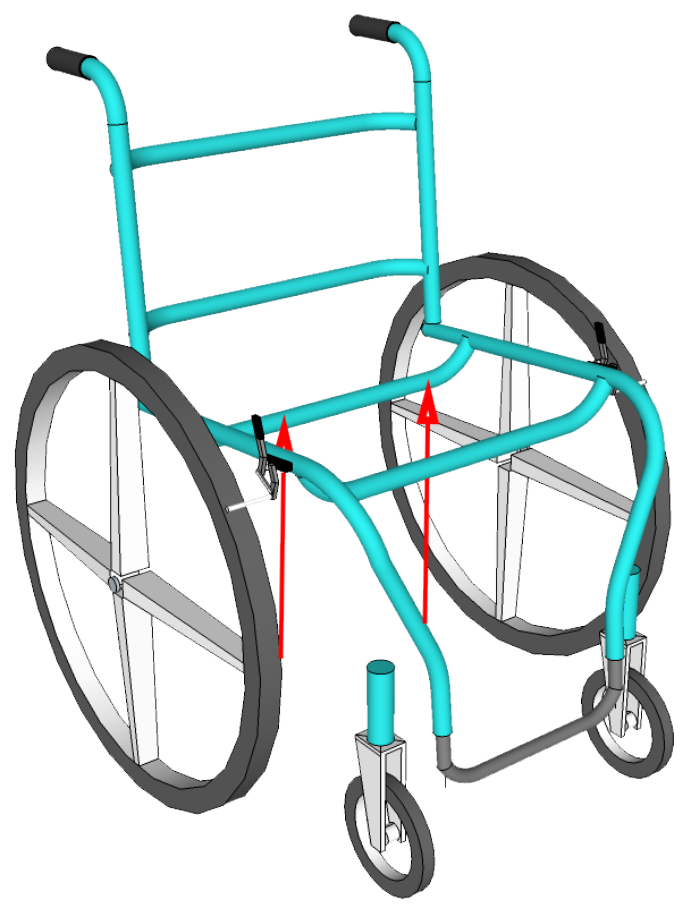

Figure 10. Coincidence of the seat frame position with the uprights prepared by the author

This second placement match also showed another possibility of coincidence in the pair of rear wheels with the last bamboo rod that is positioned transversely on the tensegrity module (figures 11 and 12) and waxed the dimensions and successfully docking between the structures of the set of use with tensegrity module.

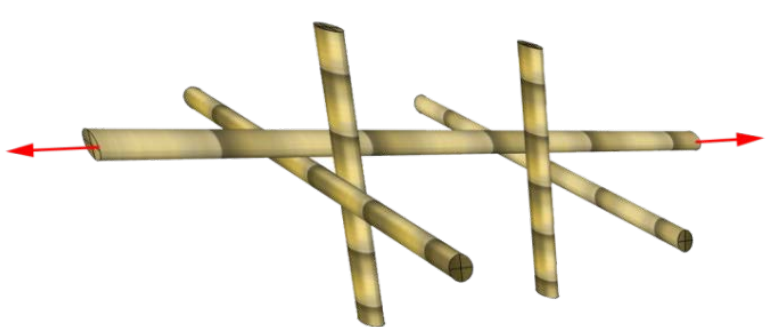

Figure 11. Tensegrity module with bamboo rod with fitting the rear wheels - prepared by the author

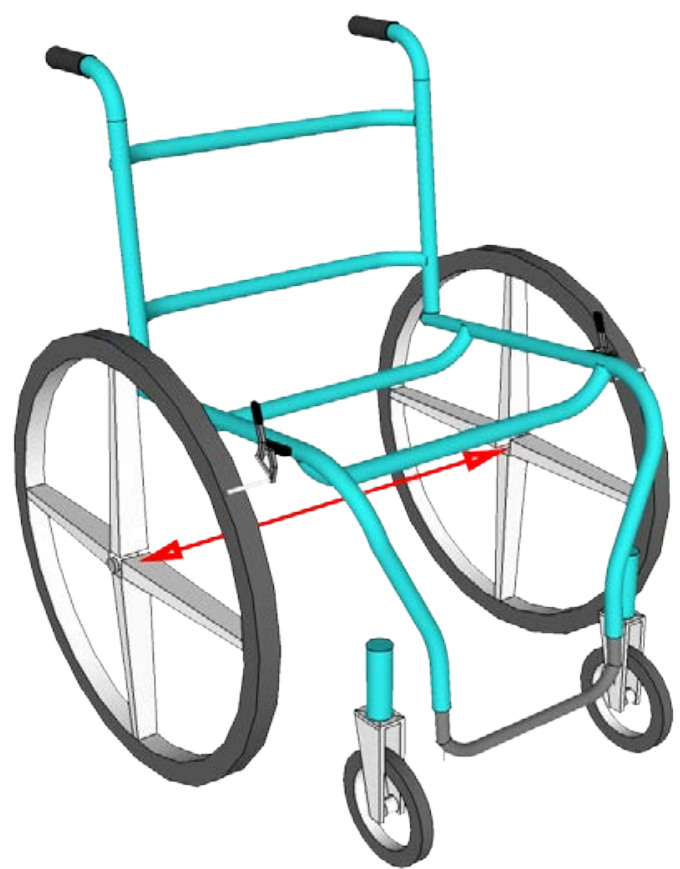

Figure 12. Coincidence of the position of the rear wheels with the transverse rod - prepared by the author

The next step was to carry out the dimensioning of the bamboo rods to adjust to the use that has measures for users with stature between 1.60-1.70, as shown in figure 13 .

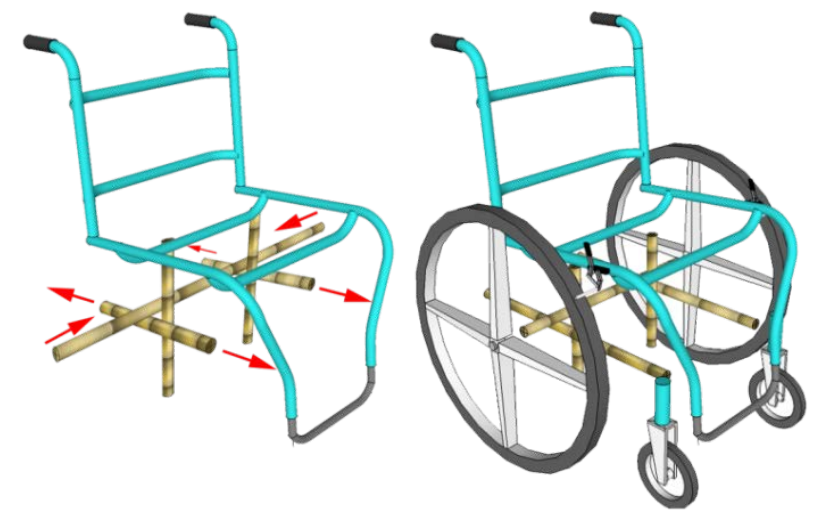

Figure 13. Tensegrity Module adjusted to the use - prepared by the author 
The design of the wheelchair tensegrity is with use and the tensegrity module attached and adjusted, ready to be finalized with the basic use items like brakes, armrests, seat and backrest tarps and the footrest. The set developed in digital 3D application can thereafter the development generate detailed technical drawings of manufacturing will give subsidies to make up the test template and feedback the test model itself.

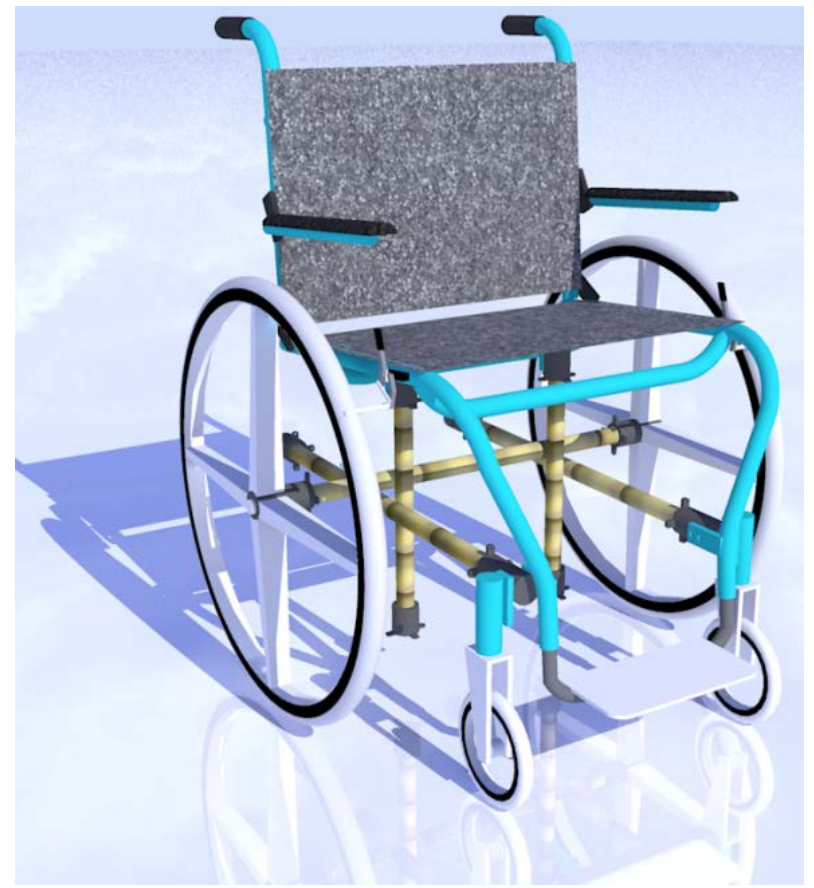

Figure 14. Prototype design the wheelchair of tensegrity structure prepared by author

\section{Methods of Production of the Prototype}

For the production of the test model was developed a template which formed the basis for the use of metal set, consisting of the backrest, seat and footrest, with tensegrity structure of bamboo, according to chapter 5 of the thesis. [9].

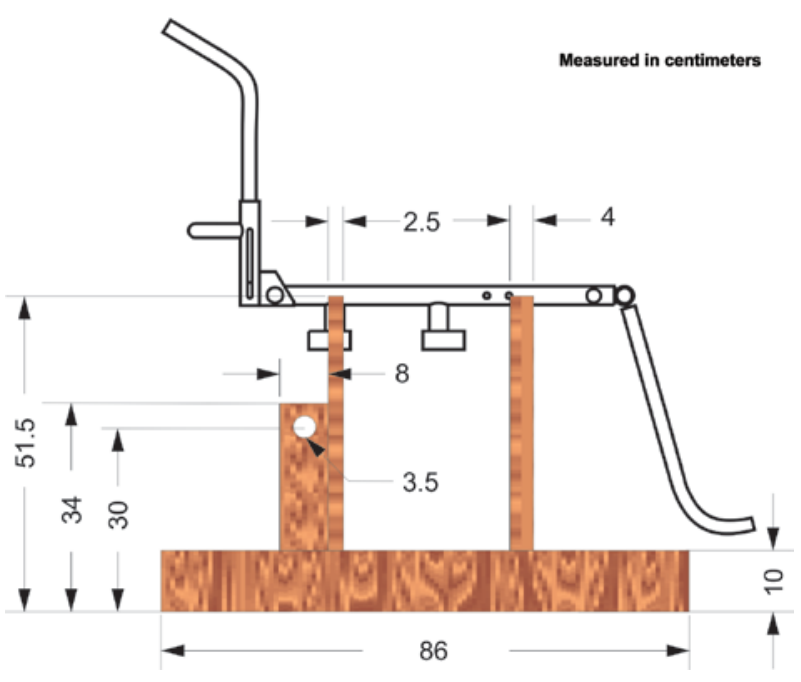

Figure 15. Technical drawing of the template for the set of use prepared by author

After defining the measures and positions as the technical drawing was started the production of the feedback of the parties that are the holders of the bamboos of tensegrity structure, this step before the final Assembly of cables. Therefore, it is extremely important that is held within the stipulated specifications. With the cabling terminated the manufacturing phase of the test model was completed successfully.

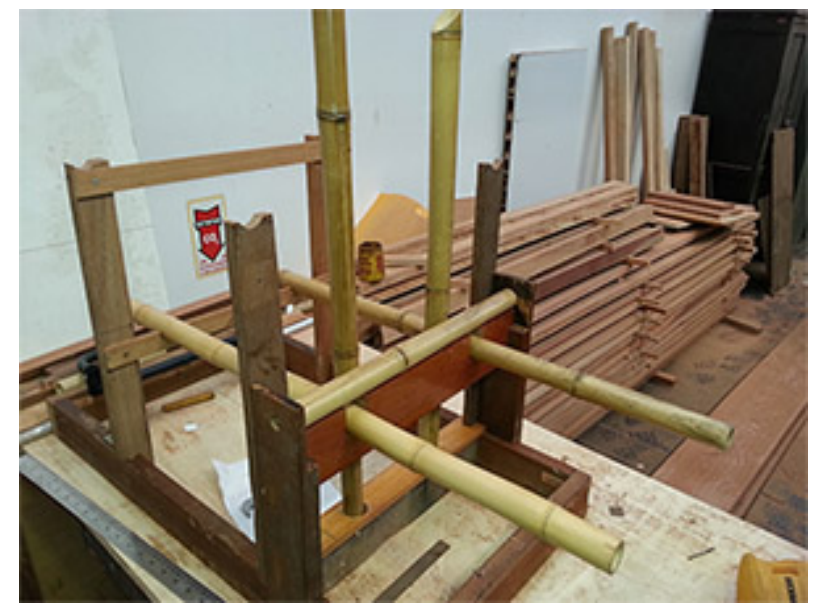

Figure 16. Gauge ready with the five rods positioned - prepared by author 
After the production of the metal connections, which will serve as the anchor cables, has begun the final Assembly of the model for the cabling.

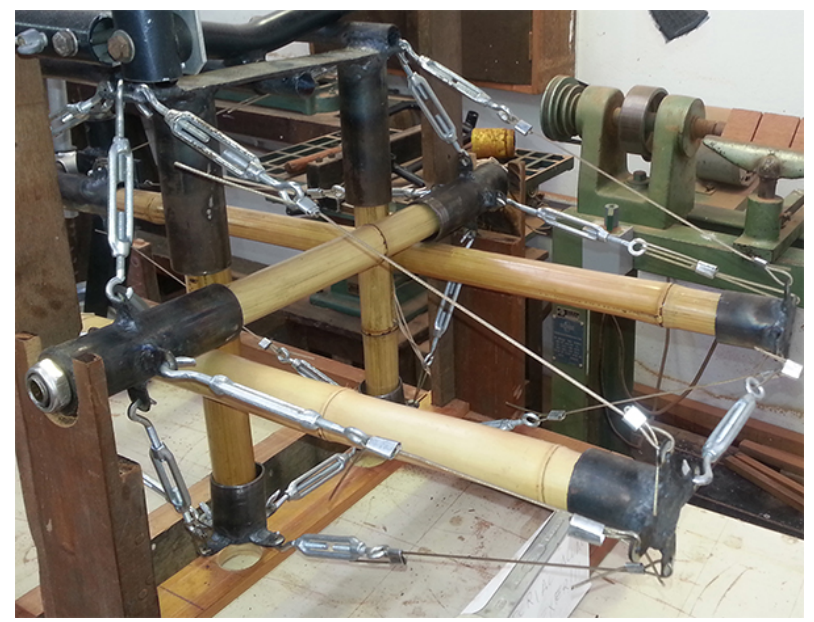

Figure 17. Gauge mounted with metal rods and connections and tensegrity structure wired - prepared by author

With the cabling terminated the manufacturing phase of the test model was completed successfully, set the application methodology of the tests.

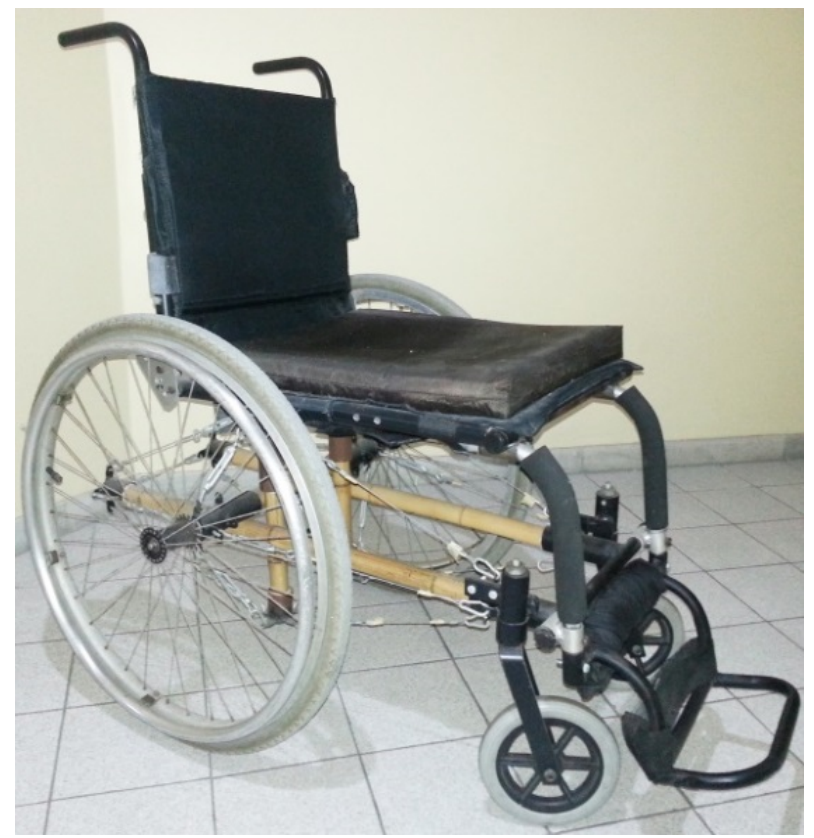

Figure 18. Test model of the wheelchair of tensegrity structure prepared by author

\section{Discussion and Evaluation of Tests}

\subsection{Evaluation of Tensegrity Structure Tests}

It should be noted that the tensegrity structure was designed to withstand loads and loads up to $120 \mathrm{~kg}$ or $198 \mathrm{lb}$ and to verify the integrity of the structure, preliminary tests of mechanical stress were carried out. These tests consisted of using the chair in various situations of use with a weight of $120 \mathrm{~kg}$ or $198 \mathrm{lb}$ and check the structure's resilience, ie if there was any deformation in the structure due to loss of tension or if some of the parts of the cabling system was damaged. The purpose of these tests was to ensure the integrity of the tensegrity structure to give safety to persons who would perform the spring effect testing, and especially to wheelchair users, who would subsequently perform daily use tests, which will be described in item 5.2.

After the mechanical stress tests to verify the integrity of the structure, two types of tests were performed: The first test was carried out by engineers, designers and professionals of the medical rehabilitation area in order to verify the spring effect of the tensegrity structure and to evaluate if it could generate a pleasant feeling and also ease the bumps in the use of the wheelchair in uneven terrain.

It was defined by the multidisciplinary group that the tests would consist of collecting information after each of them use of the tensegrity wheelchair in sidewalks and floors with rebounds and deformations in the campus facilities of the Pontifical Catholic University of Rio de Janeiro/PUC-Rio.

The conclusion of all those who carried out the tests was that the structure:

1. It is able to deform in all senses (lateral and frontal) to undergo a mechanical action and to return the original form without any type of structural problem;

2. And because it undergoes this deformation, it is capable of providing a soft feel (spring effect) that facilitates and alleviates the effects of the bump caused by uneven floors.

The experts' explanation for the physical phenomenon occurring in the wheelchair with the tensegrity structure is that when one sits in the chair the two vertical bamboo sticks that are attached to the seat (Figure 19) are pressed down to generate traction in all eight steel cables (4 cables from each bamboo stick). 


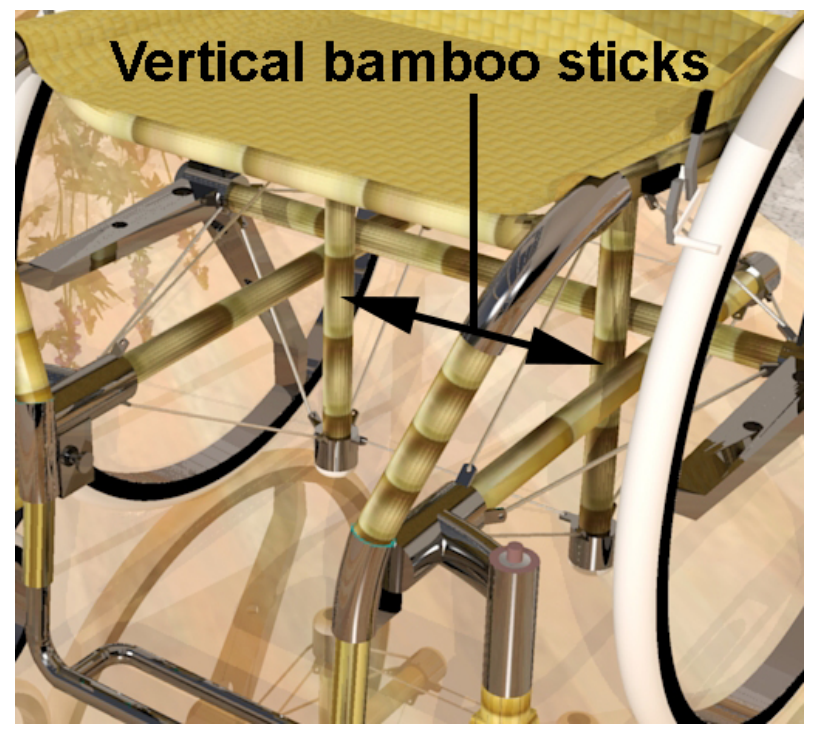

Figure 19. Vertical bamboo sticks - prepared by author

This pressure on the vertical bamboo rods consequently changes the position of the other rods in relation to the initial shape of the tensegrity structure, but since the tensegrity structure is resilient, that is, it always tends to return to its initial form when the chair is moved or passes through some irregularity in the ground, the structure tends to return to the initial shape, however by the action of the user's weight the structure will deform again. This action and reaction of deforming and returning to the initial form generates the spring effect and the sensation similar to a system with damping, according to figure 20.

\section{PRESSURE EXERTED ON VERTICAL STICKS}

\section{TRACTION ON STEEL CABLES}

\section{DEFORMATION AND RETURN TO INITIAL FORM}

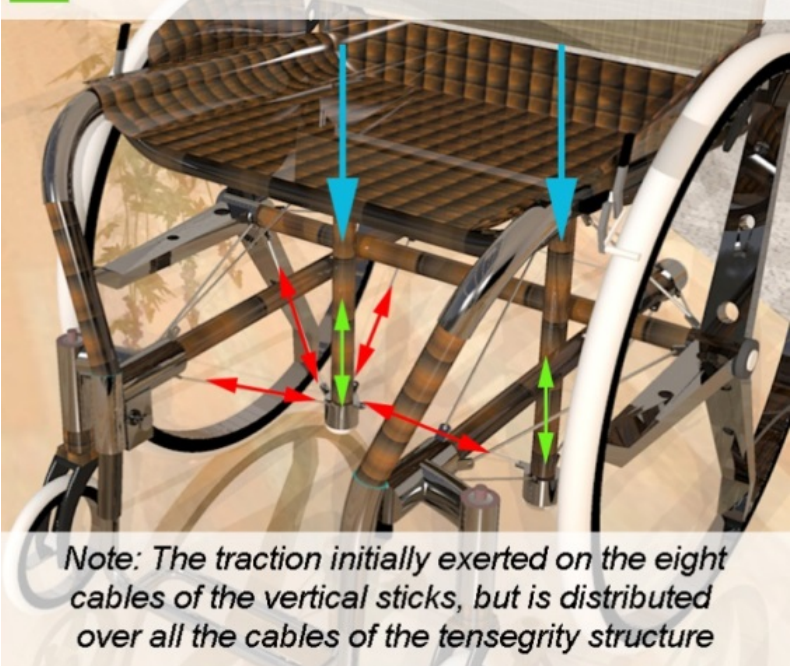

Figure 20. Distribution of forces exerted on the vertical sticks that generate tension in the cables and deformation and return of the structure to the initial shape after undergoing pressure (when sitting in the chair) prepared by author
Another advantage of the malleability of the tensegrity structure, (which was even quoted by the second user of chairs in its test), is its ease of transposition of uneasiness and unevenness in the floor, because when the front wheels encounter some obstacle the structure tensegrity deforms and manages to go over, moreover, the structure is able to absorb and minimize the impact effects.

In conventional wheelchairs, that is, without any system of damping and rigid structure, the front wheels hit and cannot pass through the obstacles. In addition, because they do not have an absorption system, the impacts received by the rigid frame chairs are directly felt by the person in the chair (Figure 21), causing great discomfort that is maximized when walking continuously on uneven ground.

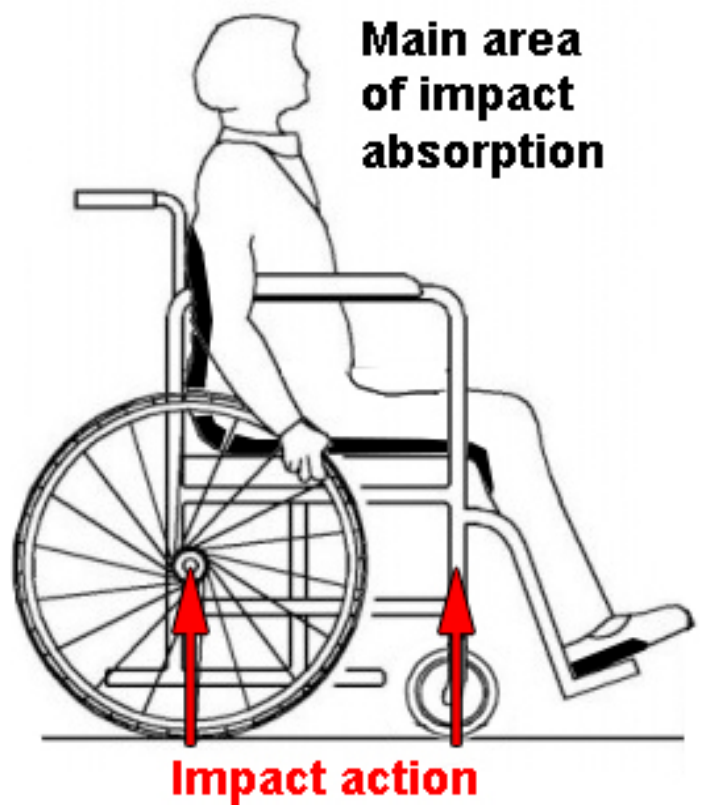

Figure 21. Impact Absorption on Rigid Structure Wheelchair - prepared by author

There are cushioning systems that can be attached to rigid-structure seats, as well as the use of special impact-absorbing cushions and front wheels, but all generate a very high cost for users. This project attempts to disseminate a technology that meets all these advantages at a lower cost and accessible to people of all walks of life.

\subsection{Evaluation of Tests with Wheelchair Users}

To structure the tests was chosen qualitative research technique called-action-research-that best shapes the needs and specifics, because this technique interferes with the field researcher where the research takes place, along with interlocutors present, i.e. There is a cooperation between the participants to solve the problem.

For the application of the practice tests, was designated by the technical advice of CVI/PUC-Rio [6], the test model of tensegrity Chair should be used by the user in your home and/or places of their daily lives to perform all functions and routine actions for two days. 
With respect to the analysis of the practical tests was defined that users should make a comparison between using their wheelchairs (activity of daily life) of rigid structure, with the test model tensegrity. Thus, users would have a parameter where analysis could evaluate the research questions in the questionnaires, which were defendants applied after the two-day trial. The interviews, if there is availability of user, would be carried out on the premises of CVI/PUC-Rio with the presence of a multidisciplinary group and so manage the result. The test user (1), the advisor (2), the researcher and a CVI commission with the clinical body composed of the Therapist (3) and the Designer (4), the CEO of CVI/PUC-Rio (5) and two guests medical rehabilitation students (6 - 7) were present, according to figure 22.

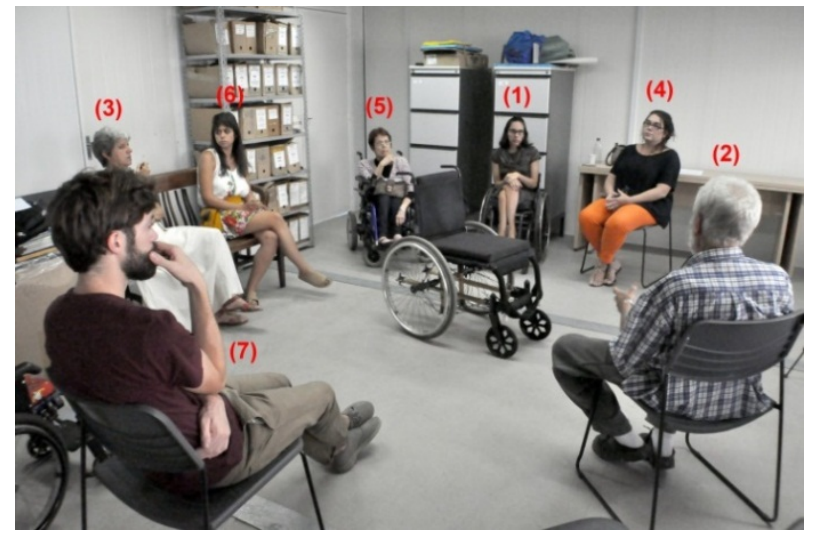

Figure 22. Multidisciplinary group on CVI/PUC-Rio - prepared by author

Thus, a detailed research process was set up to organize and order the sequence of practical tests with the user to obtain the best data.

1. Creation of questionnaire for cataloging of reports from users of wheelchairs in use of wheelchairs post-tests.

2. Choice of wheelchair users by criteria and indicate the CVI/PUC-Rio.

3. Application of tests with users to study the behavior of physically handicapped persons to the functional model simulating situations of daily use in the home of the person who will perform the test.

4. Analyses of comparisons between the use of tensegrity Chair with the Chair of the user himself.

5. Collection of the results of the practical and theoretical studies through study group composed of the supervisor of the research, the researcher, the wheelchair user and the professional group CVI/PUC-Rio.

Note: In items 3 and 5, at the time of the tests, if authorized by the author, some photos and / or videos may be collected for cataloging.

The three people who tested the wheelchair tensegrity (Figure 23) gave a favorable opinion on the question of the structure absorb impacts and provide thus greater comfort. All participants signed the term of free consent, as well as the authorization for disclosure of their names and images in scientific publications.

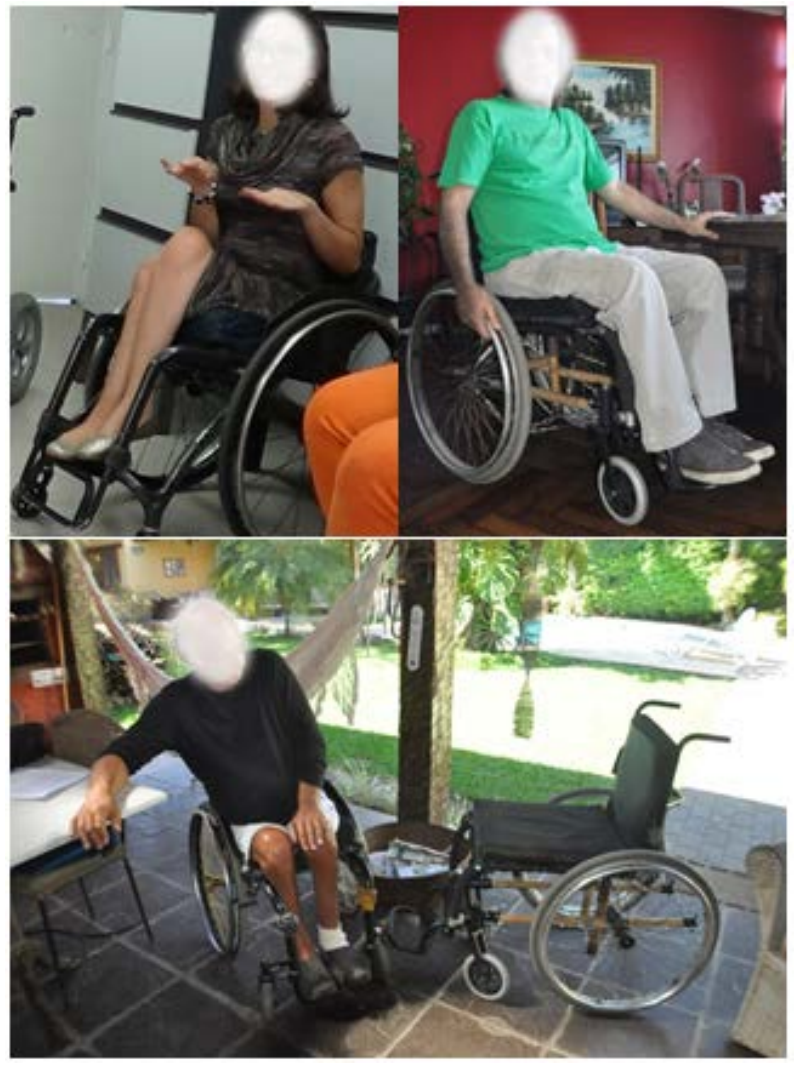

Figure 23. Group of wheelchair users who performed the tests prepared by author

The first user to test the tensegrity structure was a 33 year old woman. At first, the chair seemed strange to him by the visual aspect, but with the use in his residence he realized that the structure acts as a shock absorber and the sensation is very good and it helps to those who need to spend much time sitting in a chair to get around. By the end of the test, she had grown accustomed to the chair, and she already thought she was so strange.

The second test was a 45 year old man who made an important caveat regarding a small bump between the kitchen and the hallway that with his daily and private chair needs to perform a small maneuver by poking the front of his chair so that the wheels the front pass over. Already with the tensegrity chair he was able to transpose the rebound without the need for any extra maneuver and also did not feel any impact that would impair the handling of the chair or cause him any discomfort. He completed this analysis with an observation regarding the strength of the tensegrity structure, saying that even performing the task of transposing the rebound the structure seemed extremely strong and did not suffer any misalignment after the action, as well as, it remained very compact every day of tests.

The third test was performed by a 68 -year-old doctor and 42 years of age using a wheelchair. The Doctor is a pioneer 
in the game of tennis for wheelchair users in Brazil, including participating in several Paralympics and constantly invited to give lectures on this theme. Due to physical problems arising from many years of wheelchair use it is very difficult and painful to adapt to other wheelchairs and perform the tests for two days, as defined by the interdisciplinary team. However, with his experience in developing wheelchair designs, Doctor contributed directly to the project suggesting several changes in the design.

\section{Advantages of the Structure Tensegrity}

The tensegrity structure has a number of advantages, is lighter than rigid structures, absorbs impacts by the spring effect and thus eliminates the damper system, can use natural and renewable materials, can be assembled by fit without the need for bolts and this is easier to produce, in addition to the low maintenance cost, as shown figure 24 .

Because of these characteristics, the tensegrity structure is accessible to the low-income public, maintenance can be easily performed by the user, can be used in difficult-to-reach places with uneven terrain, can be produced on a large scale with a simple factory structure without the need for skilled labor and large machines. This makes the cost of a wheelchair tensegrity less than the cost of a steel wheelchair.

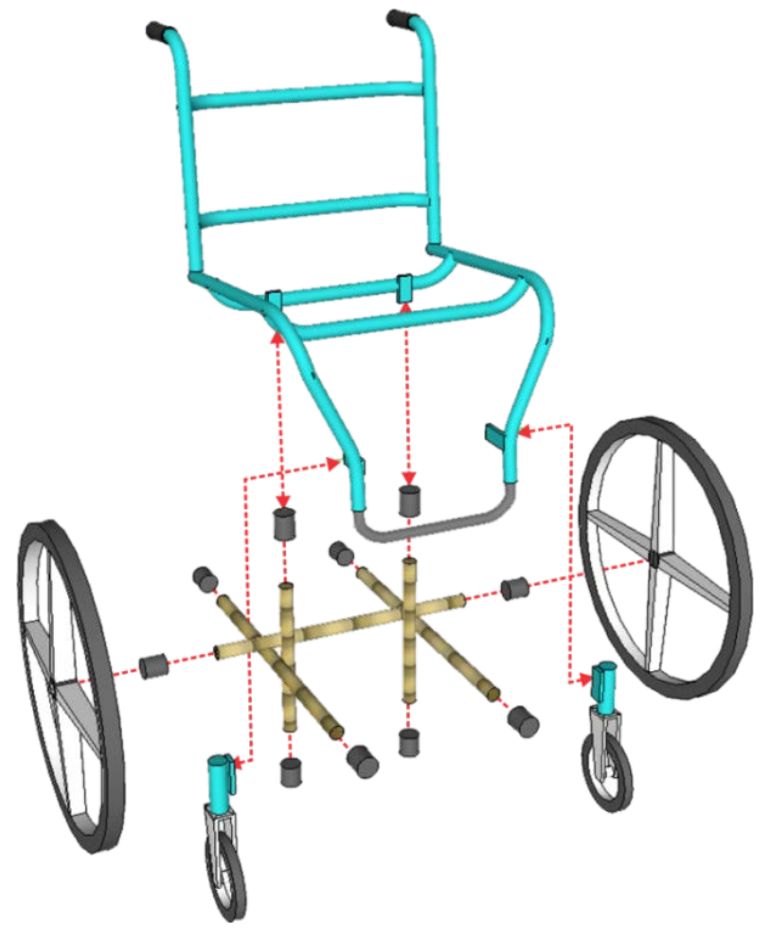

Figure 24. Exploded view of the tensegrity structure assembly which is completed with the laying of steel cables giving the traction and structural unit - prepared by author

\section{Conclusions}

At the end of the research we have come to the conclusion that all the questions presented as the problem of research objectives: General and specific, and the hypothesis formulated ${ }^{1}$ were correct and have been proven by tests. Thus, the conclusion is that the research is justified and is able to provide academic and social developments in the field of assistive technology and rehabilitation and still be applied in similar products in the structural and functional aspects that are moved the wheels.

Based on the results obtained in the research, after tests with users and discussions with the multidisciplinary group of professionals in the field of rehabilitation, were generated numerous suggestions and contributions ${ }^{2}$ to suit the design of the project needs and practices of use, as well as to new technologies and materials in the production of wheelchairs, all with the aim of improving the quality of life of the user. It was also possible to envision the possible consequences of the initial project, done for the test model, which resulted in some proposals to the Chair design and can be observed in the conceptual design proposals (Figures 25, 26, 27).

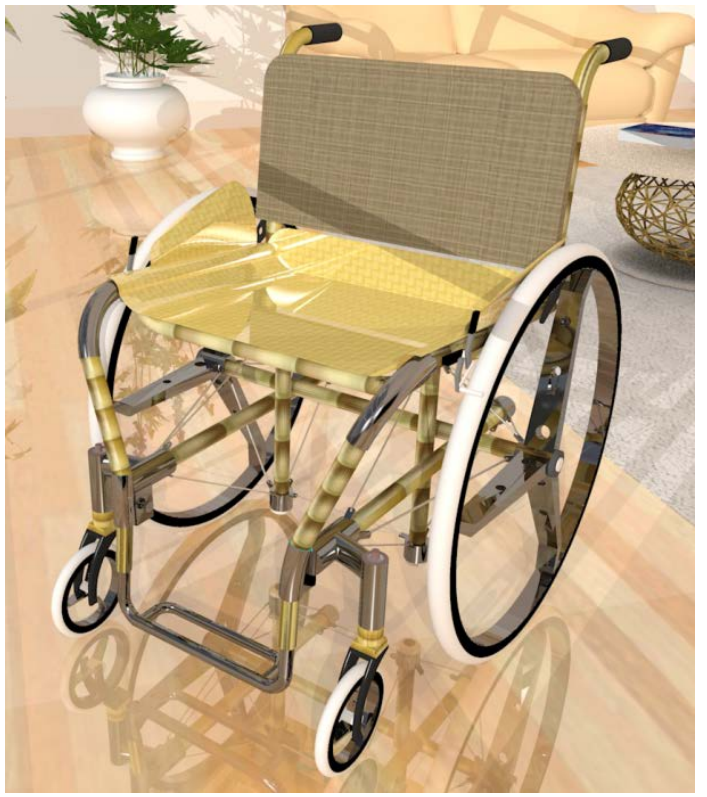

Figure 25. Conceptual proposal in natural bamboo - prepared by author

1 It is considered as hypothesis that the use of the principle known as tensegrity can be integrated and applied in the design of wheelchair meeting the usability needs of the user, making this a structural extension of the body interacting organically absorbing impacts, since tensegrity is a cable spring and bars for greater comfort.

2 The first change suggested in the initial design is the reduction of the horizontal bamboo rod at the back by $10 \mathrm{~cm}$. The second change is the inclusion of a variation of height of the use set (backrest, seat, footrest). The third suggested change is the inclusion of a quick coupling assembly to facilitate the fitting and withdrawal to transport the chair between the use set with the tensegrity structure. The fourth change was the inclusion of a front wheel spacing to increase the chair's stability and facilitate 360 -degree rotation to facilitate maneuvering. The fifth change was the lowering of the set of foot support to increase the variation of the foot and adapt to variations in the height of the lower limbs of the users. The sixth change was the inclusion of a rigid seat support. 


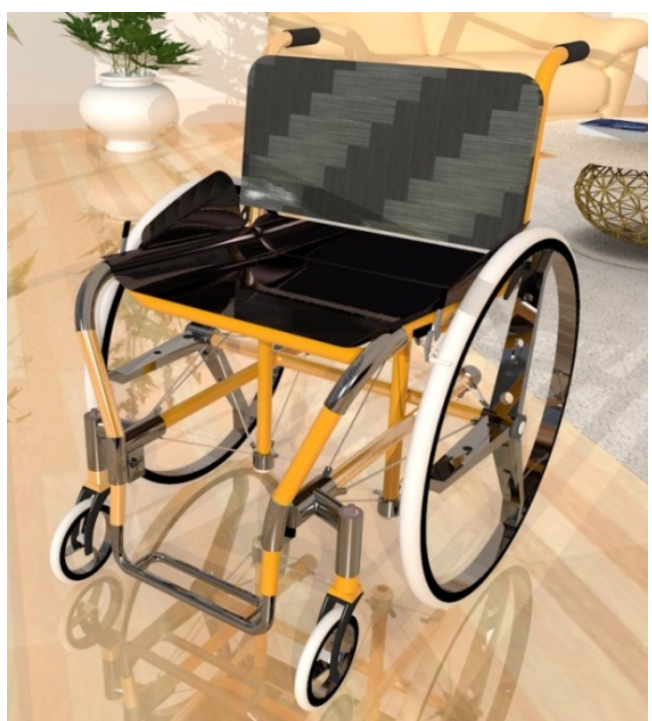

Figure 26. Concept proposal in colored bamboo - prepared by author

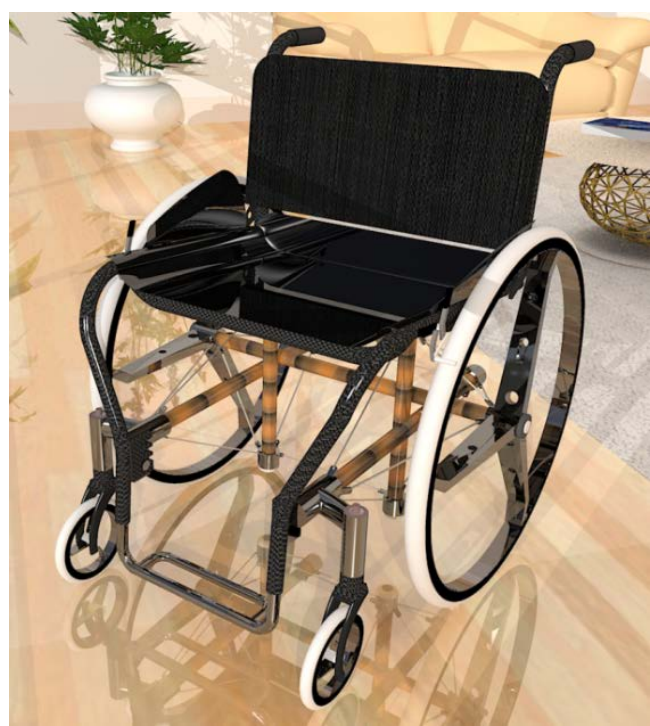

Figure 27. Hybrid conceptual proposal of metal and bamboo - prepared by author

\section{Acknowledgements}

This article could not have been written without the contributions and discussions with the advisor prof. Ripper and employees workshops on industrial design models of the Federal University of Rio de Janeiro for the production of the tensegrity wheelchair test model that provided the functional and practical analyzes of use and success of the research. I make a special thank-you to my wife, son, family, friends, assessor and reviewers. The original work was presented as a defense of the thesis of the author in the doctorate held at the Postgraduate Program in Design of the Pontifical Catholic University of Rio de Janeiro and concluded in 2016.

\section{REFERENCES}

[1] Stand-up Wheelchair, Online available from http://www.pessoaldesign.com/

[2] R. B. Fuller. Synergetics: Explorations in the Geometry of Thinking, Carrier Mamillan Publishers, London, 1995.

[3] Tensegrity, weaving and the binary world, Online available from

https://smiadotexperimentaldotcom.files.wordpress.com/20 15/01/snelson-tensegrity_and_weaving.pdf

[4] K. Ghavami. Bamboo: An Alternative Material in Engineering. The Journal of the Institute of Engineering, PUC 492/1992. Ingenuity, Technical Editor Ltda, Sâo Paulo, p. 3-7.

[5] J. L. M. Ripper. Society, Nature and Technique: Design of Adaptive Structures of Bamboo. Rio de Janeiro, 2015.

[6] CVI-PUC-Rio - Independent Living Center of the Pontifical Catholic University of Rio de Janeiro, Online available from www.cvi-rio.org.br 